\title{
On Positioning of Internet of Things Engineering Specialty of Agriculture and Forestry Universities and Construction of the Characteristics
}

\author{
Li Naixiang ${ }^{1}$, Hu Zijuan ${ }^{2}$, Yu Na ${ }^{1}$, Liu Tonghai ${ }^{1}$, Guo Peng $^{1}$ and Ma Guoqiang ${ }^{1}$ \\ ${ }^{1}$ School of Software Engineering Tianjin Agricultural University, Tianjin, China \\ ${ }^{2}$ School of Computer \& Information Engineering Tianjin Chengjian University, Tianjin, China \\ lnxtjau@126.com,673573771@qq.com
}

\begin{abstract}
This thesis analyzes the development status, characteristics, and target demand of internet of things engineering specialty, further explores the target positioning and characteristics of internet of things engineering specialty of agricultural and forestry universities combining with the demand for dislocation development of universities by the society and the trend of mass education, and provides the basic thoughts and measures of specialty construction.

Index Terms - Agricultural and forestry universities, Internet of things engineering, Target positioning, Specialty characteristics, Application orientation
\end{abstract}

\section{Current Development Status of Internet of Things Engineering Specialty}

Several years ago, internet of things engineering (sensor network) specialty was only a special major set in several universities. As the strategic new industry represented by internet of things engineering thrives, internet of things engineering specialty has developed fast. Until the end of 2011, 128 colleges and universities in China had set up internet of things engineering specialty approved by the Ministry of Education, of which Hebei Agricultural University, Shandong Agricultural University, Xinjiang Shihezi Agricultural University were listed in it[1]. In 2012, internet of things engineering specialty was formally listed in the Catalog of Majors for Undergraduate Students in Institutes of Higher Learning (2012) as the specialty of strategic new industry, and the setting of internet of things engineering specialty was approved by more agricultural and forestry universities such as Tianjin Agricultural College and ZhongKai Agricultural Engineering College. However, because this specialty has only been set up for a short time, and agricultural and forestry universities neither have successful experience for reference, nor have their own practical experience of teaching, how to operate the internet of things engineering specialty has become a subject urgently to be solved for higher education circle, especially for agricultural and forestry universities.

\section{Characteristics of Internet of Things Engineering Specialty}

Internet of things engineering is a multi-disciplinary and interdisciplinary subject set according to the demand for development of national strategic new industry, which still needs time to become an independent subject. The characteristics of the specialty are prominent.
From the aspect of its content, Internet of things engineering specialty integrates the core contents of computer, network and communication, automatic control, etc.[2], which requires students to have specialized knowledge of multidisciplines, so as to realize the objective of integrated application of multi-disciplinary technology.

From the aspect of industrial composition, in the industrial scale of tera-scale internet of things[3], the share of chip and equipment manufacturing industry as the core of industrial chain is far away from that of downstream systematic integration and application development. Its development also replies deeply on the pulling of downstream application. The cultivation of professional talents in industrial and local colleges and universities should be positioned as comprehensive internet of things and applicative engineering talents in application field.

From the aspect of application, Internet of things engineering specialty is involved in eight application fields of "smart grid", "smart traffic", "modern logistics", "intelligent agriculture", etc [4]. the colleges of different industries must build up the characteristics of their own specialty in different application fields, so as to realize the dislocation development of the same specialty in different colleges.

\section{Requirement of Mass Education for Internet of Things Engineering Specialty}

At present, application has drawn more and more attention, and it has become the worldwide trend to carry out IT professional education reform for application[5]. Chinese institutions of higher learning have realized the situation, and are carrying out the feature construction of IT specialty according to their own advantages and characteristics. They have begun to pay attention to practical teaching facing to the increasing demand for "going on duty with zero distance", increased the content and teaching hours of experiments, and strengthened the link of internship and practice of students. However, discipline-based course mode has not changed essentially, and the initiative of students is hard to be aroused. Many students only study for exams, and do not actually understand the theories. It is a mere phrase that the ability of problem solving can be promoted through experimental verification theory. It is hard for students to obtain knowledge, and is also hard for teachers to teach. The learning outcome of 
students is also not recognized by the industry. Especially at present when the higher education has been popularized, the conflicts between teaching and learning, and learning and application have become more and more serious. It is imperative to reform the discipline-based course mode thoroughly.

\section{Training Objective and Characteristics Positioning of Internet of Things Engineering Specialty of Agricultural and Forestry Universities}

At present when social demand has been diversified, disciplinary specialty education for application requires every type of schools to identify their own specialty training objective[6], and establish the discipline specialty features combining with their own advantages and characteristics, so as to realize the dislocation development of the same specialty in different colleges. Most of the students majored in internet of things engineering from higher institutes of agriculture and forestry will take up an occupation after graduation. It is undoubtedly that applicative talent training objective must be established, the key of which is to specify the objective, and identify how to establish the disciplinary specialty features according to the training objective.

Actually, the advantage of agricultural and forestry universities lies in traditional agricultural disciplines, which have unique advantage for combining internet of things and agricultural disciplines. It should identify the talent training objective for applicative internet of things engineering specialty facing to agricultural field, aim at cultivating the applicative talents of internet of things in agricultural field, and make full use of one's own resource advantage, so as to form distinguish disciplinary specialty features, and realize the dislocation development with the same disciplinary specialty in engineering-related colleges.

Based on such a precondition, internet of things engineering specialty of agricultural and forestry universities must target at "agricultural application oriented positioning", "establishment of compound knowledge structure", "cultivation of technology-intensive capability" and "training of engineering realization method", strive to solve the specific and real problems during the teaching, and form their own specialty features.

\section{Thoughts and Measures of Specialty Construction}

During the construction and development of internet of things engineering, higher institutes of agriculture and forestry, especially local agricultural and forestry colleges, must accurately grasp the positioning of engineering application ability training of professional and technical talents of internet of things engineering, make deep research and trial for construction of the specialty features of internet of things engineering by combining with their own industrial advantages, and form operable construction plan of specialty features through the practicing process of what to teach - how to teach - content planning - resource construction - teaching implementation - result evaluation. They should make full use of original IT education resource, stick to the principle of experimenting when researching and improving when concluding, and strive to make innovation in special courses, textbooks and practical teaching.

For specialty construction, it should stick to the principle of teaching research and innovation testing orientation, take teaching staff construction as the base, and professional laboratory and practical teaching base construction as the support, and focus on the concept of "learning by doing", and the teaching mode and mechanism exploration of practice integration. It should consider the integration of all kinds of knowledge and instruments, and connection of different training links at the overall height, so as to form the operation mechanism integrating theory and practice. It must combine the actual condition of the school, and apply the following measures flexibly:

\section{A. Strengthening the research and teaching experiment of talent training of internet of things engineering}

Since 1990s, IT education of Chinese universities and colleges has experienced reform and development. At present, almost all the universities and colleges depend on the practical teaching reform carried out by IT practical training institutes and enterprises. However, the real effect is still less than satisfactory due to many subjective and objective reasons. Especially for the newly established IT specialties such as internet of things engineering, it is absolutely necessary to strengthen the research and teaching experiment of talent training. The research and teaching experiment must be firstly carried out according to the following key contents:

1) Requirements for knowledge structure and post business capability of the talents of internet of things applicative engineering.

2) Fully implementing the integrated featured course system with the concept of "learning by doing".

3) Training mode of new applicative engineering talents and cooperative mechanism between school and research institute, and school and enterprise.

4) Talent evaluation standard, appraisal mode and method in different stages.

5) Featured textbooks and teaching resources favorable for "task driven" and "case teaching" practice

B. Establishing the teaching staff matching with the professional talent training objective

Based on the positioning of talent training objective of internet of things engineering specialty of agricultural and forestry universities, teaching staff construction must be carried out according to the featured course system construction and the actual need of teaching practice. It should combine introduction with cultivation. When introducing teachers, it should not only pay attention to the title, educational background and expression ability of teachers, but should also focus on their applicative and manipulative ability, knowledge structure and exploration spirit. The talents with compound knowledge structure (agricultural background knowledge + professional knowledge), rich experience of 
agricultural application projects and practical exploration spirit of education should be the first choice. The academic degree of teachers of IT specialty in agricultural and forestry universities is generally low with little experience in scientific research. The task for training and promoting the ability of onjob teachers is tough. Strict system of further education and practicing should be formulated to form effective incentive mechanism. On one hand, it should encourage teachers to study for doctor's degree or make postdoctoral research in state-level agricultural R\&D institutions and domestic firstclass colleges. On the other hand, it should encourage teachers to take exercise in enterprises and grass-roots scientific research institutions, get familiar with the work there, improve the research and development ability and manipulative ability, and get adapted to the requirement of professional practical teaching for the practical ability of teachers.

\section{Focusing on the construction of agricultural applicative laboratory and practical base of internet of things}

It is one of the major tasks of the new specialty to construct the laboratory and practical teaching base. As a multi-disciplinary and interdisciplinary new specialty, the task of laboratory construction for internet of things engineering is even tougher. Fortunately, the specialties of electronic information engineering, communication engineering, computer science and technology, software engineering, automation, and measurement \& control technology and apparatus have already been set in most of the colleges with certain condition of experimenting and practicing, which makes it possible for experimental resource sharing. Therefore, repeated investment should be avoided in the construction of laboratory and practical teaching base of internet of things engineering specialty. Besides the core laboratories such as the newly-built RFID, all kinds of original laboratories and offcampus practicing bases should be fully used to form the basic experimental and practicing platform of the specialty with the principle of resource sharing. It should focus on the construction of featured laboratories and practicing bases for internet of things integration and application in agricultural field, such as the construction of measurement and control laboratory of facility agricultural environment, and $3 \mathrm{~S}$ technology and precision agriculture laboratory, and cooperate with large facility planting and breeding enterprises to establish off-campus agricultural application practical teaching base of internet of things engineering, so as to provide powerful support for the teaching of featured specialty application.

D. Focusing on the development of characteristic textbooks and teaching resources of internet of things engineering specialty

Textbooks and teaching materials are the basic components for course teaching practice. The choice and organization of contents should meet the specific course teaching requirement, and should also be convenient for the implementation of advanced teaching methods to improve the teaching effect. At present, textbook compilation of internet of things engineering specialty has just started. Especially for the internet of things engineering specialty of agricultural and forestry colleges, the applicative teaching material for internet of things engineering specialty in agricultural field is still blank. In order to meet the requirement of characteristic teaching in agricultural application field, all schools should support and encourage teachers to compile the characteristic specialty textbooks and internal teaching materials of internet of things engineering in agricultural application, such as Facility Environment Measurement \& Control Network, RFID and Facility Fishery, and Agricultural Intelligent Decision. Meanwhile, a batch of basic core textbooks should be compiled according to the application of the teaching methods such as "task driven method" and "case teaching" based on the current course books of electronics, communications, control and computer, and the change of teaching requirements on internet of things engineering specialty after the re-planning of teaching cases, knowledge content, experimental content, and organizational mode, so as to create the basic condition for core curriculum construction.

\section{Acknowledgment}

Funding project: one of the research achievements of undergraduate education quality and key subject of teaching reform research planning of Tianjin regular institutions of higher education: Research on the Applicative Characteristics Construction of Internet of Things Engineering Specialty (JIN JIAO WEI GAO [2012] No. 32).

\section{References}

[1] Seting the IoT professional institutions list(revised edition,2010-2012 The school provided statistical list IoT Professional)[DB].Baidu LibraryProfessional data-Humanities and Social Sciences, http://wenku.baidu.com/view/61bf4cf0ba0d4a7302763a52.html

[2] Zhang Guanghui, Yu Huangjing," On Professional Quality of Internet of Things and Training Objectives",Science \& Technology Information, 2011 no.11,pp.216-217,April 2011

[3] Bai Aning, Song Junfang, Li Li," Research on docking IoT of college talent cultivation and industrial", Journal of Nanchang College,vol.27,no.3,pp.66-67+134,June 2012

[4] Liu Haitao, Ma Jian, Xiong Yongping. Technical Application of the Internet of Things, BeiJing: Machinery Industry Press,2011

[5] Ma Haiyan. "IT Education Should Improve with Time - Examining the Transformation and Integration of Oversea IT Education". Internet Dissemination,2005 no.8,pp.54-55, August 2005

[6] Zhang Aishu, Jiang Shu, Du Yanliang. "Study on the Orientation of Different Types of Institutions of Higher Learning”. Journal of Chlna University of Mining \& Technology(Social Sciences) ,2004 no.4,pp.7680,December 2004 